\title{
Evaluation of the compression process diagram in presence of magnesium stearate
}

\author{
Hossein Asgarirad ${ }^{1 *}$, Claus Führer ${ }^{2}$ \\ ${ }^{1}$ Department of Pharmaceutics, Faculty of Pharmacy, Mazandaran University of Medical Sciences, Sari, Iran \\ ${ }^{2}$ Department of Pharmaceutical Technology, TU Braunschweig, Germany
}

Received: Dec 3, 2015, Revised: Dec 25, 2015, Accepted: Jan 30, 2016

\begin{abstract}
In the pharmaceutical industry is no longer worked without instrumented tablet presses. The recording of the press information at different parameters of each test series and batches in the development of tablets and an online measurement and control of pressing forces during the production process is becoming increasingly important. Eccentric tablet presses were equipped with sensors for the upper and lower punch force and upper punch way. As sample quantity $100 \mathrm{~g}$ were selected. All fillers lubricant mixtures were prepared in Turbula lab mixtures with $68 \mathrm{rpm}$. The bulk and tap density of the excipients were determined according to DIN of 53912 and 53194 on a tap density testers into a $250 \mathrm{~mL}$ graduated cylinder. It is to be expected that compression diagrams are changed by lubricant additives. This should give itself to recognize in the different section of the force relationship. This study also showed that the lubricant properties of a lubricant can be greatly influenced by the interaction between the lubricant and ingredient formulation to be exposed.
\end{abstract}

Keywords: Compression process diagram, magnesium stearate, lubricant, eccentric tablet press.

\section{Pharm Biomed Res 2016; 1(4): 59-64～DOI: 10.18869/acadpub.pbr.1.4.59}

\section{Introduction}

Lubricants are used mainly for compression in tableting. The task of the lubricants exists is the decrease of the size of contact points, as a layer, which possesses even a low shearing strength and will not easily break through can, between which rubbing surfaces is put. The lubricants decrease the range of the reciprocal effect to places, where the surfaces touch themselves, and inhibition of the sliding procedure which increase of the contact points. The distribution of lubricant on the particle surface by one lines up examined by many researchers and the results contradicted to attempt distribution of magnesium stearate particle on substance surface and it is shown that magnesium stearate could not cover the surface as monomolecular coverage (1), but magnesium stearate particle at the granulates surface is adsorbed. The fundamental work for the description of the compression procedure at the tableting originate from the powder metallurgy $(2,3)$, the work for the theory of pressing powdered raw ores from the pharmaceutical range $(4,5)$. In the pharmaceutical industry is no longer worked without instrumented 
tablet presses. The recording of the press information at different parameters of each test series and batches in the development of tablets and an online measurement and control of pressing forces during the production process is becoming increasingly important. Eccentric tablet presses can be equipped with sensors for the upper and lower punch force. The energies of compression and the ratio of elastic to plastic energies increased with increase in compression speed. This was because the material was becoming more elastic and more energy was required for the elastic expansion leading to a reduction in the energy available for plastic deformation and bond formation which resulted in a decrease in tensile strengths (6). The lack of significant increase in solid fraction and low tablet tensile strength for lactose upon compression is likely due to its brittle fragmentation and some elasticrecovery as shown by the high flexural modulus (7). The results of study indicate that addition of microcrystalline cellulose in the formulation in levels between $10 \%$ and $30 \%$ significantly improve the tablet hardness at lower tablet compression forces (8). Pregelatinized starch, $\alpha$-lactose monohydrate and tribasic calcium phosphate were used as model substances. The results indicate the high precision of the incremental displacement transducer and reveal the characteristic differences between the plastic-elastic and brittle nature of the excipients used in this study (9). The evaluation on compression behavior of powder and granules can also through parameters of force -time, displacement-time and force- displacement diagrams takes place division the one strength- away- circles into the single surfaces describe E1, E2 and E3 into the literature is frequently described (10).
The patch E2 supplies a statement about the irreversible deformation and the surface E3 contains information about elastic recovery of a substance (11). Due to their deformation behavior the pharmaceutical materials can be divided roughly into plastic and brittle materials. In recent times an evaluation method was developed to the descriptive parameters of pressing force -time- curves at cyclic testing tablet presses (12). By strain gauge (DMS) and/or piezo-electric load cells and an inductive displacement transducer it is possible, which in a tableting machine of arising forces with the respective position of the pressing tools instrumentation to pursue at the same time (13). Most work for the theory of energy balance is based on force way curves (10).

\section{Materials and methods}

\section{Materials}

Microcrystalline cellulose (Avicel®PH101, FMC,USA) and Calcium hydrogen phosphate (Emcopress ${ }^{\circledR}$, parmentier, D-Frankfurt) were used for preparing standard formulations. Different concentrations of magnesium stearate (Baerlocher, DMuenchen) was used as lubricant.

Various formulations were prepared of using different additives with different concentration of magnesium stearate, followed by further mixing.

The particle size distribution of the used model substances were determined by sieve analysis according to DIN 4188. As sample quantity $100 \mathrm{~g}$ were selected. All fillers lubricant mixtures was prepared in Turbula labmixtures, type T2c (1 X $220 \mathrm{v}$, $50 \mathrm{~Hz}, \quad 120 \quad$ W), with 68 
rpm. The bulk and tap density of the excipients were determined according to DIN of 53912 and 53194 on a tap density testers into a $250 \mathrm{ml}$ graduated cylinder. The tableting was accomplished into one eccentric tableting machine E 11F (Fette Co., Schwarzenbek). The tablet machine is instrumented with stain gauge and an inductive displacement transducers instrument.

Carrier wave frequency bridge PR 9307, Philips (way) and KWS 3071, Hottinger Baldwin (strength). The strain gauge measuring points present on the upper punch- and lower punch holder were calibrated the inductive displacement measuring devices. For the processing that from the measuring bridges resulting singles these became with a A/D- converter $(17000 \mathrm{~Hz}$.) and a computer taken up and stored. The programs necessary for the evaluation were written in turbo-Pascal (14). An eccentric machine was equipped with biplane punches of 10 and $20 \mathrm{~mm}$ diameter. The filling took place always with standing machine by hand.

\section{Evaluation of tablets}

The uniformity of weight is evaluated according to the DAB Germany pharmacopoeia. The disintegration time of the tablets is determined according to the DAB Germany pharmacopoeia.The crushing strength is determined using a Erweka TBT, Erweka-Apparatebau, DFranfurt am main for ten tablets. The compositions of formulations are listed in table 1.

\section{Results}

In an orienting test series the machine was adjusted in such a way that over all accomplished compression of the lower punch in the same position it was and so that the free die area had a height of $9.55 \mathrm{~mm} .500 \mathrm{mg}$ of the investigated powder was delivered to the die. A mixture of dibasic calcium phosphate $(80 \%)$ and micro-microcrystalline cellulose (20\%) were selected as substance in these models test. The immersing way of the upper punch was stopped in such a way that all tablets with the same pressing force were injected by approximately $1,2 \mathrm{KN}$. Beside the admission of the force way diagrams became the breaking strength of the resulting tables, which decay time and so called $\mathrm{R}$ value, i.e. the relationship of the lower punch force to the upper punch force in the compression maximum determined.

In the following diagrams the point of immersing of the punch is into the die, on the abscissa with A, with B the point of contact of the punches with the filled in substance halls, with $\mathrm{C}$ the terminator point of the pre-compression, with $\mathrm{D}$ the lower dead center of the upper punch, with $E$ the possible of the lower punch and with $F$ the position designates, at which the upper punch in the relaxation phase loses the contact with the substance after the compression. Thus geometry of the compression is described. The diagrams in illustration 1 and 2 show the force process curves of the lubricant free powder substance fig. 1 and the powder substance under mixing of $0.5 \%$ magnesium stearate (Figure 2). The diagrams prove that the expected extent be-being that point of the first contact of the upper punch with the substance to a deeper position in the die shifted.

The height of the substance column decreased there after about $10 \%$, which the appropriate decrease of the bulk volume correlation that end of the precompression has itself with the attempts 
accomplished with magnesium stearate in relation to attempt without lubricants to somewhat deeper position shifted. This corresponds also to the conception that in consequences of the lowered friction the powder bed can be more easily pushed together and that without considerable energy expenditure closer packing to be developed to be able. Usually it could be observed however that the appropriate values varied around the value of the lubricant-free attempt.

Table 1. Comparison of the geometrical data and physical properties of compression process

\begin{tabular}{lllll}
\hline characteristics & $\begin{array}{l}\text { Filler* } \\
100 \%\end{array}$ & $\begin{array}{l}\text { Mg- } \\
\text { St. } \\
0.5 \%\end{array}$ & $\begin{array}{l}\text { Mg- } \\
\text { St. } \\
1 \%\end{array}$ & $\begin{array}{l}\text { Mg- } \\
\text { St. } \\
2 \%\end{array}$ \\
\hline Point F (mm) & 3.85 & 3.78 & 3.75 & 3.75 \\
\hline Point B (mm) & 9.55 & 8.60 & 8.60 & 8.50 \\
\hline Point C (mm) & 7.90 & 7.20 & 7.20 & 7.20 \\
\hline Point D (mm) & 3.70 & 3.57 & 3.55 & 3.55 \\
\hline $\begin{array}{l}\text { Bulk vol. } \\
\text { (ml/100g) }\end{array}$ & 150 & 135 & 135 & 133 \\
\hline $\begin{array}{l}\text { Top vol. } \\
\text { (ml/100g) }\end{array}$ & 124 & 112 & 112 & 112 \\
$\begin{array}{l}\text { Tablet } \\
\text { Hardness (N) }\end{array}$ & 120 & 31 & 31 & 30 \\
\hline $\begin{array}{l}\text { Disintegration } \\
\text { Time (min) }\end{array}$ & 0.20 & 1.80 & 4.60 & 5.50 \\
\hline R - Value & 0.69 & 0.89 & 0.86 & 0.86 \\
\hline $\begin{array}{l}\text { Mech. Energy } \\
\text { loss (Nm) }\end{array}$ & 0.84 & 0.72 & 0.69 & 0.64 \\
\hline $\begin{array}{l}* \text { Fillers: Dibasic calcium phosphate (80\%) } \\
\text { Avicel@PH101 (20\%) }\end{array}$ & & & \\
\hline
\end{tabular}

\section{Discussion}

If one compares these observations with the break strength of the appropriate tablet, then one observes that interestingly enough the magnesium stearate tablets exhibits a substantially smaller breaking strength despite its clearly height density than lubricant free the this witnesses from a reduction of the interparticles adhesion. In the following table 1 the values of the crushing strength, disintegration time, the mechanical loss of energy are shown with the compression and the R-value. As the table exhibits, the R-value under the influence of magnesium stearate increases with very small concentrations significantly over then again insignificant to decrease. The R-value shows the relationship from lower punch force to upper punch force in the maximum compression. It represents thus indirectly friction conditions at the die wall at the moment to the highest compression. The values of the mechanical loss of the energy, which are represented by the surface, included the curve stretch of force-displacement diagram. The mechanical loss of energy comes off primarily by the irreversible deformation of the particle.

This is the smaller, the more easily the particle with the compression to derive together can and the pushed punch movement by change of situation evade. The smaller thus the interparticle friction, the smaller should be the value of the mechanical loss of energy. The compression is introduced by the precompression phase i.e. an almost strength less process of the diagram, which are through characterized that the particles evade to the punch penetrating into the die together by a simple change of position an glide. This phase is terminated, if a significant force rise begins. The pre-compression the main compression follows, which is characterized by the fact that the particles, which can glide now no longer together, are plastic deformed or broken. The break procedure or the 
plastic deformation arises, if an elastic deformation preceded and the break relations way yield point, which is characterized by a certain material stress, were exceeded.

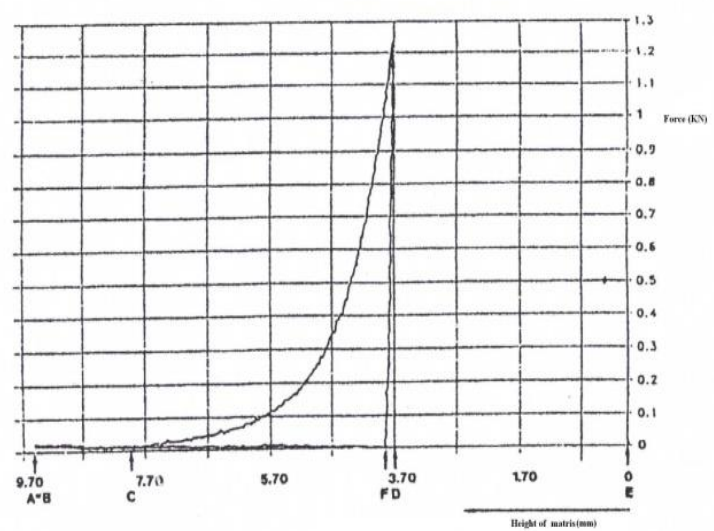

Figure 1 Diagram of pressure displacement plot in the energy analysis without magnesium stearate

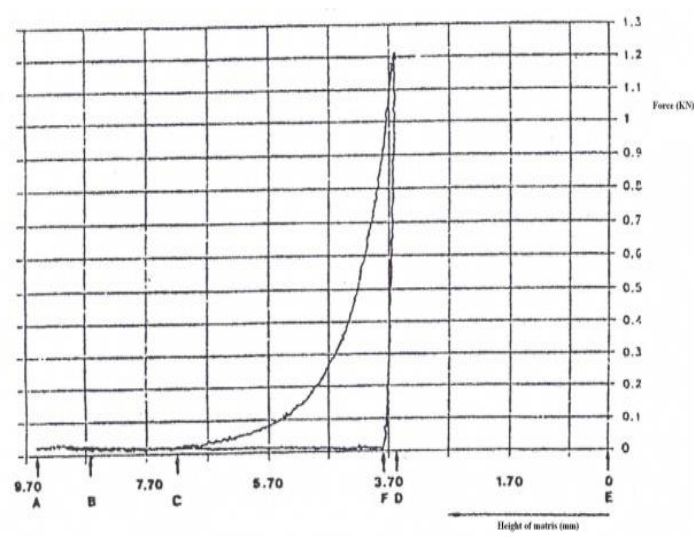

Figure 2 Diagram of pressure displacement plot in the energy analysis with $0.5 \%$ magnesium stearate.

\section{References}

1. Lerk CF. Film formation by magnesium stearate during mixing and its effect on tabletting. Pharm Weekblad 1975;110:317.

2. Unckel H, Arch FD. Processes during compression of metal powders. Archiv fuer das Eisenhuettenwesen1945;18:161.

3. Ballhausen C. Contribution to theoretical and practical aspects of compressing powders. Archiv fuer das Eisenhuettenwesen 1951; 22:185-96.

\section{Conclusion}

It is to be expected that compression diagrams are changed by lubricant additives. This should give itself to recognize in the different section of the force relationship. These procedures presuppose an interparticle friction, which leads in the long run only to the necessary shear stresses. To that extent it is to be expected that also the force rise branch in its form can be affected by lubricant additives. The force rise, which represents the middle material stress arising in the press materials, would have to thus run under the effect of lubricants flatter and lead with a given immersing way to a deeper pressing force in the compression maximum.

\section{Conflict of interest}

The authors declared no potential conflict of interest with respect to the authorship, and/or publication of this study.
4. Fuehrer C. Ueber die Theorie der Vorgaenge bei der Pulverkompression. Chem Ing Tech 1971;43:849.

5. Craik D J, Miller B F. The flow properties of powders under humid conditions. J Pharm Pharmaco 1958;10:136-44 .

6. Akande OF, Rubinstein $\mathrm{MH}$, Rowe $\mathrm{PH}$, Ford JL. Effect of compression speeds on the compaction properties of a 1:1 paracetamolmicrocrystalline cellulose mixture prepared by 
single compression and by combinations of precompression and main-compression. Int $\mathrm{J}$ of Pharmaceutics 1997;157:127-36.

7. Iyer R.M. The impact of roller compaction and tablet compression on physicomechanical properties of pharmaceutical excipients, Pharmaceutical Development and Technology 2014;19;583-92.

8. Golchert D. Evaluation of some compression aids in tabletting of roller compacted swellable core drug layer. Int $\mathrm{J}$ of Pharmaceutics 2013;157:322-8

9. Dressler JA. Comparison of Incremental and Inductive Displacement Transducers on an eccentric tablet press. Pharm Ind 2001;66:88693.

10. Nelson E, Busse L W, Higuchi T. The physics of tablet compression VII: Determination of energy expenditure in the tablet compression process. J Am Pharm Assoc Sci Ed 1955;44:223-5.
11. Dürr M, Hanssen D, Harwalik H, Kennzahlen zur Beurteilung der Verpreßbarkeit von Pulvern und Granulaten. Pharm Ind 1972;34:905-11.

12. Koch $H$. Bewertung der Presseigenschaften pharmazeutischer Wirk-und Hiflsstoffe anhand von Presskraft- Zeit-Kurven. Dissertation, University Marburg 1990;160-2.

13. Parmentier W. Untersuchungen zur Gesetzmaessigkeit des Kraftverlaufs bei der Tablettierung. Dissertation, TU Braunschweig; 1974;153-4.

14. Baehr MUE. Study the structure and bonding mechanism of cellulose powder with special consideration mechanically crushed products. Dissertation, TU Braunschweig 1990;141-2. 